\title{
A Recombinant Truncated Cry1Ca Protein Is Toxic to Lepidopteran Insects and Forms Large Cuboidal Crystals in Insect Cells
}

\author{
Raimundo W. S. Aguiar, ${ }^{1}$ Érica S. Martins, ${ }^{1,2}$ Fernando H. Valicente, ${ }^{3}$ Newton P. Carneiro, ${ }^{3}$ Andréia C. Batista, ${ }^{2}$ \\ Viviane M. Melatti, ${ }^{2}$ Rose G. Monnerat, ${ }^{2}$ Bergmann M. Ribeiro ${ }^{1}$ \\ ${ }^{1}$ Cell Biology Department, University of Brasília, 70910-900, Brasília, DF, Brazil \\ ${ }^{2}$ Embrapa-Recursos Genéticos e Biotecnologia, C.P. 02372, 70770-900, Brasília, DF, Brazil \\ ${ }^{3}$ Embrapa-Milho e Sorgo, 35701-970, Sete Lagoas, MG, Brazil
}

Received: 20 December 2005 / Accepted: 7 April 2006

\begin{abstract}
A truncated version of the crylCa gene from Bacillus thuringiensis was introduced into the genome of Autographa californica multiple nucleopolyhedrovirus (AcMNPV) under the control of two promoters. A recombinant virus (vSyncry1c) was isolated and used to infect insect cells in culture and insect larvae. Structural and ultrastructural analysis of insects infected with vSyncry1C showed the formation of large cuboidal crystals inside the cytoplasm of insect cells in culture and in insect cadavers late in infection. Infected insect cell extracts were analyzed by SDS-PAGE and Western blot and showed the presence of a $65-\mathrm{kDa}$ polypeptide probably corresponding to the protease processed form of the toxin. Bioassays using purified recombinant toxin crystals showed a $\mathrm{CL}_{50}$ of $19.49 \mathrm{ng} / \mathrm{ml}$ for $2^{\text {nd }}$ instar A. gemmatalis larvae and $114.1 \mathrm{ng} / \mathrm{ml}$ for $S$. frugiperda.
\end{abstract}

Bacillus thuringiensis (Bt) is an entomopathogenic Gram-positive bacteria that produces crystals composed of insecticidal proteins during sporulation. These toxins are called Cry proteins or $\delta$-endotoxins, which can be highly toxic and specific to susceptible insects and at the same time have no toxic effects on other organisms, including other insects [7]. The mode of action of Cry proteins starts with the ingestion of toxin crystals by a susceptible insect, where in the alkaline environment of the midgut, these crystals are dissolved and the protein processed proteolitically to an active form. The activated toxin interacts with proteins in the membrane of columnar cells, forming pores that will cause the loss of cell contents and membrane potential, which leads to cell swelling and death. The insect quickly stops feeding and eventually dies [7]. Cry protein specificity is dependent on the binding of the active form of the toxin to the midgut membrane of susceptible insets [12]. More than 300 Cry protein genes have been cloned and sequenced from different strains of $B t$ [6] and the amino acid sequence of these proteins is the main criteria for their classification [6].

Correspondence to: Bergmann M. Ribeiro; email: bergmann@unb.br
The cryl gene family codes for proteins with a molecular mass of around 130 to $140 \mathrm{kDa}$, which forms mainly bipyramidal crystals during sporulation [7]. The cry $1 \mathrm{Ca}$ gene was first described by Honée et al. [13] and its product showed toxic activity to Spodoptera exigua (Hübner) (Lepidoptera: Noctuidae), Spodoptera litura (Fabricius) (Lepidoptera, Noctuidae), Helicoverpa armigera (Hübner) (Lepidoptera: Noctuidae), and Plutella xylostella (Linnaeus) (Lepidoptera: Plutellidae) [5, 16, 22] and due to their toxicity to these important insect pests, the crylCa genes have been used for the construction of transgenic plants $[5,16]$.

The Lepidopteran insect pests that have the most economical impact on the maize culture in México, South and Central America is Spodoptera frugiperda (Lepidoptera: Noctuidae). This insect shows low susceptibility to Cry proteins from B. thuringiensis subsp. Kurstaki, which is usually used for its control [3]. Another important lepidopteran insect pest in Brazil is Anticarsia gemmatalis (Lepidoptera: Noctuidae). This insect is the main defoliator pest in soybeans and is highly susceptible to Cry1 toxins [2].

Baculoviruses are biological control agents used in agriculture and also one of the most popular vectors 
(BEVs) for heterologous gene expression in insect cells [14], due to the presence of strong promoters (p10 and polyhedrin promoters) that allow a high level of heterologous protein expression late in infection. BEVs have been used to express full-length and truncated forms of Cry proteins from $B t[17,19,20,21]$ and fusion of a Cry protein with the main protein of baculovirus occlusion bodies (OBs) [4]. In the present study, we have introduced a truncated version of the crylCa gene into the genome of a baculovirus and analyzed the recombinant protein expression in cultured insect cells and insect larvae. Furthermore, we have shown that the recombinant protein produced cuboidal-shaped crystals and was toxic to second instar S. frugiperda and A. gemmatalis larvae.

\section{Materials and Methods}

Cells and Viruses. Trichoplusia $n i$ (BTI-Tn5B1-4) [11] cells were maintained at $27^{\circ} \mathrm{C}$ in $\mathrm{TC}-100$ medium supplemented with $10 \%$ fetal bovine serum (Invitrogen). This cell line served as host for the in vitro propagation of Autographa californica multiple nucelopolyhedrovirus (AcMNPV) and the recombinant virus vSyngalVI-, which contains the $\beta$-galactosidase gene in the polyhedrin locus [18], and was used for the construction of the recombinant baculovirus containing the crylCa (this work).

Recombinant Vírus Construction. A truncated version (2415 bp) of the crylCa gene $(3570 \mathrm{bp})$ from the B. thuringiensis strain 1644 (Embrapa Maize \& Sorghum, Brazil) was amplified by PCR reactions using specific oligonucleotide primers (F1, 5'-CCTTTTAGGATCCTT ATGGAG- ${ }^{\prime}$ and R1, 5'-CCAGATCTGCAGGAACAATCTAGATCA GGATTC- $3^{\prime}$ ). The F1 primer anneals at the $5^{\prime}$ end of the crylCa gene (the start codon of the gene is shown in italics). The R1 primer anneals at 2444 to 2469 nucleotides after the start codon. The Bam $\mathrm{HI}$ and $B g l$ II restriction site were introduced into the sequence of the primers (underlined sequence). The amplified fragment $(67.6 \%$ of the fulllength gene) was cloned into the plasmid pGEM-T easy (Promega) following the manufacturer's instructions and sequenced (MEGA BACE 1000, Amersham Bioscience). DNA from the recombinant plasmid (pGEMcry1C) was digested with Eco RI and separated by electrophoresis in a $0.8 \%$ agarose gel. The 2415 -bp fragment was gelpurified using the GFX Kit (Amersham) and cloned into the transfer vector pSynXIVVI+X3 previously digested with Eco RI [18]. One microgram of the recombinant plasmid (pSyncry1C) DNA and $0.5 \mu \mathrm{g}$ of vSyngalVI-DNA, previously linearized with the restriction enzyme Bsu 36I, were co-transfected into a monolayer of BTI-TN5B1-4 cells $\left(10^{6}\right.$ cells) in a $60-\mathrm{mm}$ plate, using liposomes (Cellfectin ${ }^{\circledR}$ from Invitrogen). The plate was incubated one week at $27^{\circ} \mathrm{C}$, when the supernatant was collected and used to purify the recombinant virus through end-point dilution in 96-well plates [18].

Recombinant Protein Expression. Six-well plates (TPP) were seeded with BTI-TN5B1-4 cells $\left(10^{6} /\right.$ well) and infected with wild-type AcMNPV and different recombinant viruses (10 pfu/cell). After $1 \mathrm{~h}$ (zero times p.i.), virus inoculum was removed and the plates incubated at $27^{\circ} \mathrm{C}$. Ninety-six hours p.i, cells were collected by centrifugation $(1000 \mathrm{~g} / 5 \mathrm{~min})$ and stored at $-80^{\circ} \mathrm{C}$. Thirty third-instar $S$. frugiperda larvae were infected with the recombinant $\mathrm{vSyncry} 1 \mathrm{C}$ by injection of virus $\left(5 \times 10^{5} \mathrm{pfu}\right)$ into the hemocoel using a microserynge (Hamilton). At $120 \mathrm{~h}$ p.i, dead larvae were collected and kept at $-80^{\circ} \mathrm{C}$. Infected insect cells and dead insect extracts were suspended in a small volume of PBS (136 mM NaCl, 1,4 mM KH${ }_{2} \mathrm{PO}_{4}, 2,6 \mathrm{mM} \mathrm{KCl}, 8 \mathrm{mM}$ $\mathrm{Na} 2 \mathrm{HPO}_{4} \cdot 2 \mathrm{H}_{2} \mathrm{O}, \mathrm{pH}$ 7.4) and proteins were fractionated in a $12 \%$ SDS-PAGE [15] using a Mini-Protean apparatus and following the manufacturer's instructions (Bio-Rad). After electrophoresis, proteins were blotted onto PVDF membranes (Millipore) using the Trans-Blot $\AA$ SD device, following the manufacturer's instructions (Bio-Rad). A polyclonal antibody raised against the Cry1Ca protein and the Western Breeze $^{T M}$ Immunodetection Kit (Invitrogen) was used to detect the recombinant protein. The polyclonal antibody was produced from gelpurified recombinant Cry1Ca protein.

Structural and Ultra-Structural Analysis of Putative Cry1Ca Crystals Produced in Insect Cells and Larvae. Insect cells were infected with AcMNPV and vSyncry $1 \mathrm{C}$ as described above and at $96 \mathrm{~h}$ p.i., analyzed in a light microscope (Axiovert 100, Zeiss), and photographed. One hundred third-instar S. frugiperda larvae were infected with the recombinant vSyncry $1 \mathrm{C}$ by injection of virus as described above, and at $120 \mathrm{~h}$ p.i., OBs and protein crystals were purified following the protocol described by O'Reilly et al. [18]. The purified $\mathrm{OBs}$ and crystals were processed for Scanning electron microscopy and analyzed under a Jeol JSM 840 scanning electron microscope at $10-\mathrm{Kv}$.

Bioassays. Different doses of purified polyhedra and recombinant Cry 1 Ca protein from insect cadavers $\left(30 \mu \mathrm{L}\right.$ containing $30,000 \times 10^{-3}$, $3,000 \times 10^{-3}, 300 \times 10^{-3}, 30 \times 10^{-3}, 3 \times 10^{-3}, 0.3 \times 10^{-3}, 0.03 \times 10^{-3}$, $0.003 \times 10^{-3}, 0.0003 \times 10^{-3}$ and $0.00003 \times 10^{-3} \mathrm{ng} / \mathrm{ml}$, respectively) were spread over the insect diet and 24 second instar $S$. frugiperda and A. gemmatalis were incubated with each dose. The quantification of the recombinant protein was carried out using the Bradford reagent following the manufacturer's instructions (Bio-Rad). Insect mortality was scored at 24 and $48 \mathrm{~h}$ post-inoculation. $\mathrm{CL}_{50}$ was determined by Probit analysis [9].

\section{Results}

Construction and Isolation of the Recombinant Virus vSyncry1C. A truncated crylCa gene (2415 bp) was cloned into the plasmid pGEMT-easy (not shown) and sequenced. The sequence showed a truncated protein $(804$ amino acid) identical to the first 824 amino acids of the Cry1Ca protein (1189 amino acids) described by Honée et al. [13] with the exception of a 20 -amino acid deletion between amino acids 589 and 608 (not shown). The crylCa gene was then cloned into the transfer vector pSynXIVVI+X3 (Fig. 1A). The recombinant plasmid pSyncry1C (Fig. 1B) was co-transfected into insect cells with linearized vSynGalVI- DNA (Fig. 1C) and the recombinant vSyncry $1 \mathrm{C}$ was isolated (Fig. 1D).

\section{Recombinant Protein Expression Analysis. BTI- TN5B1-4 cells were infected with different recombinant viruses and at $96 \mathrm{~h}$ p.i. cell extracts were analyzed by SDS-PAGE and Western blot (Fig. 2A and 2B). A protein of around $65 \mathrm{kDa}$ was detected in vSyncry1C-infected cell extracts and vSyncry1C- infected $S$. frugiperda larval extracts using an antibody raised against the Cry1Ca protein (Fig. 2B).}


A
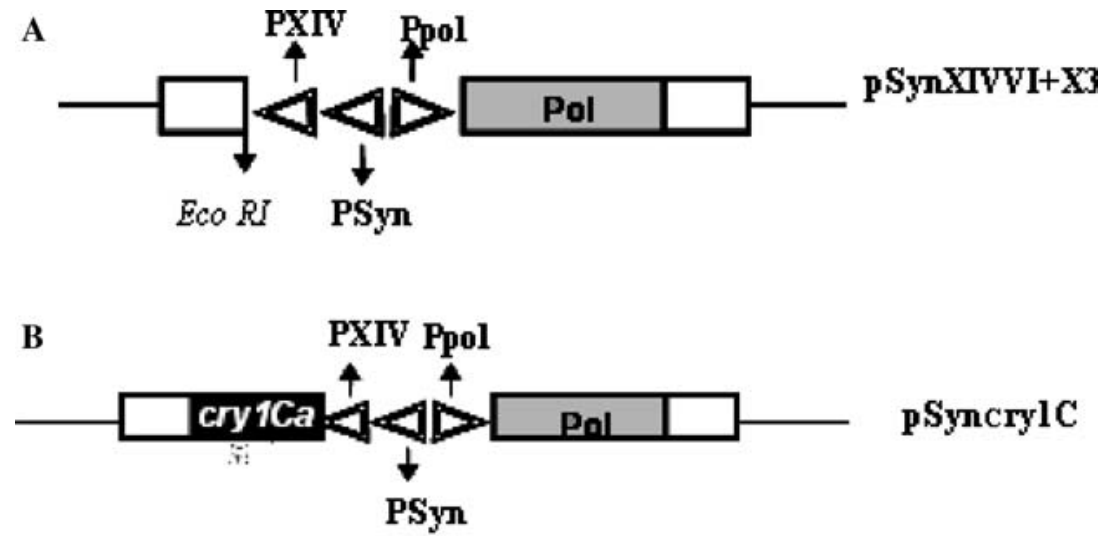

C

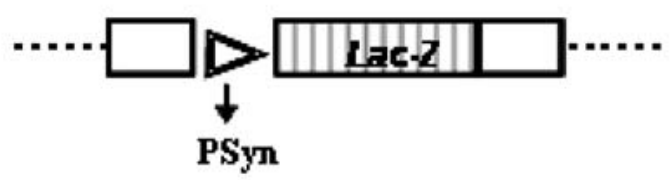

vSyngalvI-

vSyncrylC

Fig. 1. Diagram showing the polyhedrin locus in the different plasmids and virus used in this work. (A) Plasmid pSynXIVVI+X3, (B) plasmid pSyncry1C, (C) Virus vSyngalVIand (D) Virus vSyncry1C. The crylCa gene was cloned into the Eco RI site in the plasmid pSynXIVVI+X3 which was used in a cotransfection with DNA from the vSyngalVI-

D

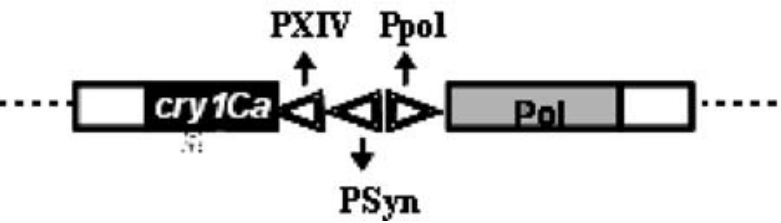
in insect cells for the construction of the recombinant vSyncry1C. The position of the pol (polyhedrin), lac- $Z$ ( $\beta$-galactosidase) and crylCa genes and their promoters (PXIV, Ppol and PSyn) are indicated.

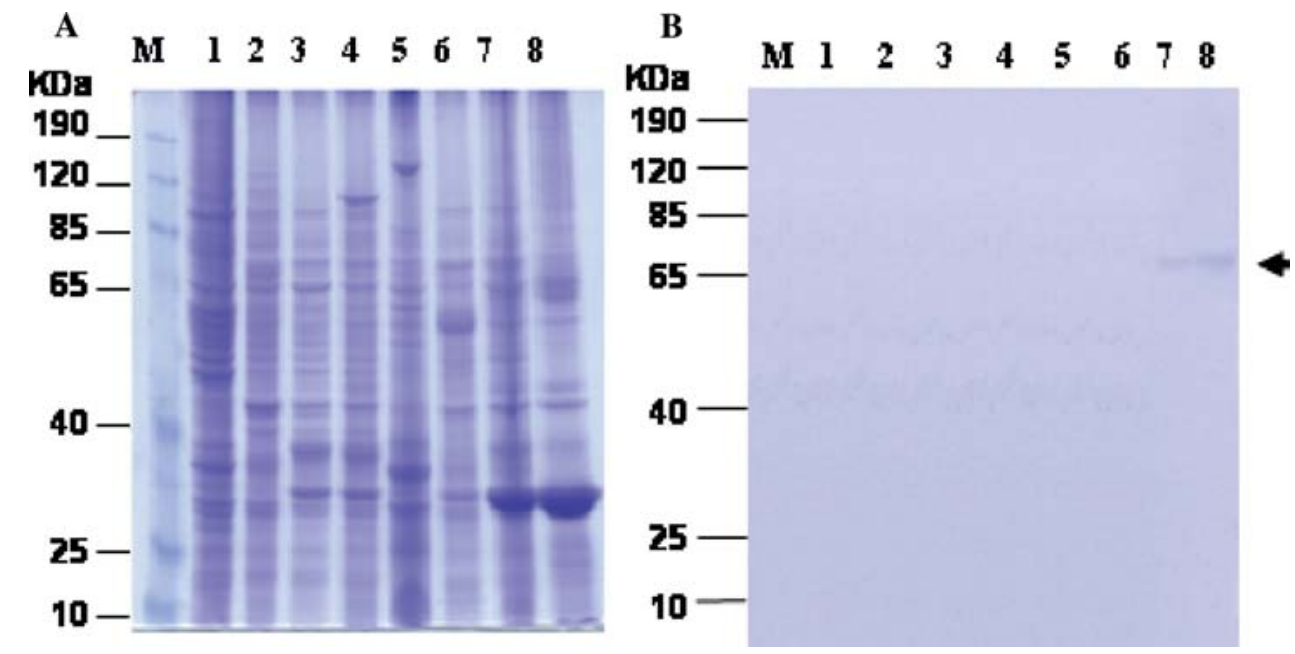

Fig. 2. Recombinant protein expression analysis. (A) 12\% SDS-PAGE containing mock infected cells (lane 1), and cell extracts from BTI-TN5B14 infected with vSyngalVI- (lane 2), AcMNPV (lane 3), vSynprotD (lane 4), vAcBtm (lane 5), vSynYFE (lane 6), and vSyncry1C (lane 7). Lane 8 shows extract from $S$. frugiperda larvae infected with the vSyncry1C. (B) Immunoblot of a similar gel shown in A using an antibody raised against the recombinant Cry1C protein. The arrow shows the labeling of a $65 \mathrm{kDa}$ protein in BTI-TN5B1-4 cells and S. frugiperda extracts. M is the molecular mass marker (Bench Mark, Invitrogen). The recombinant viruses vSynprotD, vAcBtm and vSynYFE have the protease gene from dengue virus, $c r y l A b$ gene from $B$. thuringiensis and envelope protein gene from the yellow fever virus, respectively.

Structural and Ultra-Structural Analysis of Putative Cry1Ca Crystals Produced in Insect Cells and Larvae. T. $n i$ cells cells and third-instar S. frugiperda larvae infected with the vSyncry1C produced large cuboidal crystals that were visualized by light (Fig. 3A) and scanning electron microscopy (Fig. 3B). 
A I

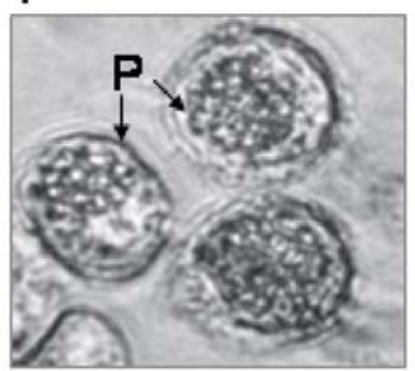

B IV

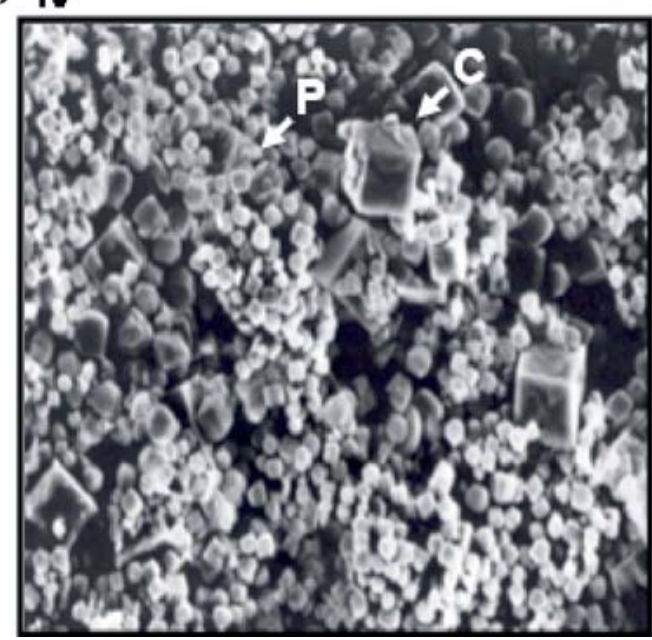

II

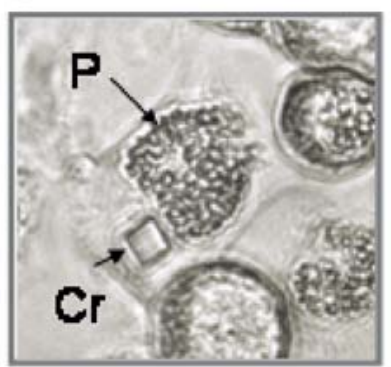

III

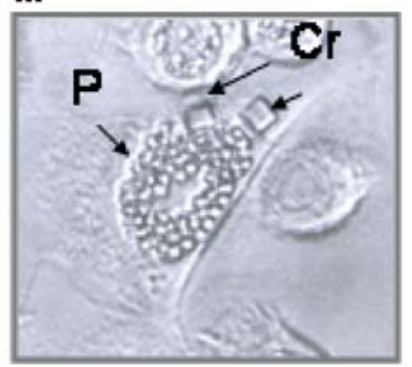

V

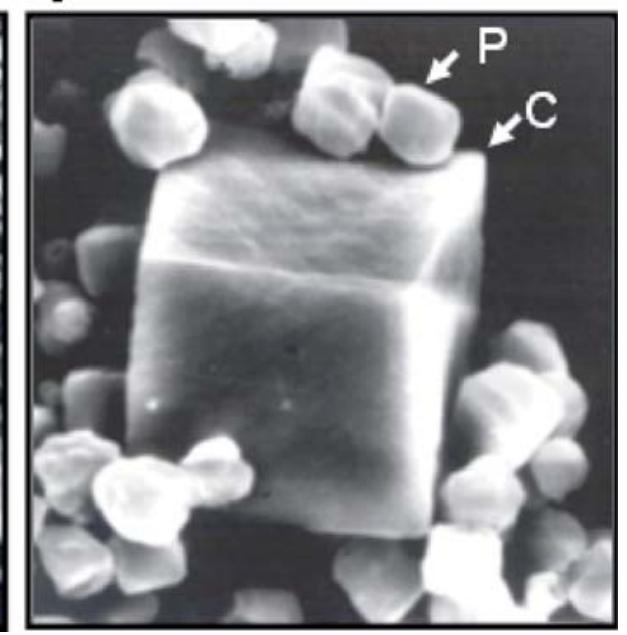

Fig. 3. Structural and ultra-structural analysis of putative Cry1Ca crystals produced in insect cells and larvae. (A) Light microscopy of BTITN5B1-4 cells infected with AcMNPV (I) at $96 \mathrm{~h}$ p.i. and with the recombinant vSyncry1C (II and III). Polyhedra (P) and crystals (Cr) are shown with arrows. (B) Ultrastructural analysis of vSynCry1C purified crystals (IV and V). Scanning electron microscopy of purified viral occlusion bodies, also known as polyhedra $(\mathrm{P})$ and crystals $(\mathrm{C})$ from $S$. frugiperda larvae infected with the recombinant vSyncry1C.

Table 1. Bioassay with purified polyhera and crystals from insect cadavers infected with the recombinant virus vSyncrylC.

\begin{tabular}{llll}
\hline Insects & CL50 $(\mathrm{ng} / \mathrm{mL})$ & Fiducial limits & $X^{2}$ \\
\hline S. frugiperda & 114.44 & $32.17 / 529.62$ & 4.68 \\
A. gemmatalis & 19.49 & $4.91 / 156.88$ & 2.38
\end{tabular}

Twenty'second-instar larvae from A. gemmatalis and S. frugiperda were used for each dose in the bioassay. The results are from three separate experiments.

Bioassays. The $\mathrm{CL}_{50}$ for $A$. gemmatalis and S. frugiperda were $19.49 \mathrm{ng} / \mathrm{ml}$ and $114.44 \mathrm{ng} / \mathrm{ml}$, respectively (Table 1). However, no statistic difference was found since the fiducial limits overlapped. Therefore, both insects are similarly susceptible to the truncated Cry1Ca toxin.

\section{Discussion}

A truncated version of a cry $1 \mathrm{Ca}$ gene from $\mathrm{B}$. thuringiensis strain 1644 was inserted into the baculovirus Ac-
MNPV genome under the control of two promoters (Psyn and PXIV) arranged in tandem for the construction of the recombinant vSyncry1C. $T$. $n i$ cells and third instar $S$. frugiperda larvae were infected with vSyncry1C and extracts showed a polypeptide, not present in wild type virus and other recombinant viruse-infected cells and insects, of around $65 \mathrm{kDa}$ in SDS-PAGE. This polypeptide probably corresponds to the $\mathrm{Cry} 1 \mathrm{Ca}$ protein processed by insect proteases. The Cry1 proteins from B. thuringiensis are synthesized as large precursors (protoxins), which are cleaved by insect gut proteases to 
form active toxins of around $65 \mathrm{kDa}$ [7]. The expression of cry genes in insect cells using BEVs can be an alternative method for the study of single Cry proteins. Some Cry proteins have already been expressed in insect cells using BEVs, such as Cry1Ab, Cry1Ac [20, 21] and Cry11Aa [19], showing that the recombinant proteins were biologically similar to their native counterparts, with toxicity towards different insects. However, the pathogenicity of the recombinant baculovirus was not improved. On the other hand, when the Cry1 Ab protein was expressed as a fused protein with the virus main occlusion body protein (polyhedrin), the recombinant virus showed an improvement in its pathogenicity against $P$. xylostella larvae [4].

Although truncated, the recombinant Cry $1 \mathrm{Ca}$ showed toxicity to second instar $S$. frugiperda $\mathrm{CL}_{50}$ $144.44 \mathrm{ng} / \mathrm{ml}$ and A. gemmatalis $\mathrm{CL}_{50}-19.49 \mathrm{ng} / \mathrm{ml}$ larvae (Table 1). This was expected since a fragment of around 1989 bp coding for a Cry1Ca protein with approximately 663 amino acids was recently expressed in tobacco and protected the plant from S. litura [16].

Despite the fact that one third of the Cry1Ca protein (approximately 365 amino acids), expressed in insect cells by the recombinant vSyncry $1 \mathrm{C}$, is absent from the C-terminal region and a 20-amino acid deletion between amino acids 589 and 608 , of the recombinant protein expressed in this work, the protein was capable of forming large cuboidal crystals in the cytoplasm of infected cells (Fig. 2). The formation of crystals by Cry proteins in insect cells infected with recombinant baculoviruses has been reported for the Cry1Ab, Cry1Ac, and Cry11Aa proteins $[17,19,20,21]$. These recombinant proteins were expressed in high amounts and some formed larger crystals than when expressed in $B t$, suggesting that the size of the crystal produced in $B t$ is limited by the size of the bacteria [21]. In a previous work, one of us has shown the formation of crystals from truncated versions of the Cry $1 \mathrm{Ab}$ protein in insect cells [21]. However, the amounts of crystals were reduced when compared to the expressed full-length protein. Some authors correlate the crystal formation with the presence of cysteine residues in the c-terminal region of the cry proteins, which are responsible for disulfide bond formation and have been suggested to be important in the formation of such crystals [1]. The Cry1Ca protein has 19 cysteine residues and the truncated version expressed in this work has only 11 . Therefore, the 8 cysteine residues absent from the truncated Cry $1 \mathrm{Ca}$ protein are not essential for crystal formation in insect cells. Besides that, recent studies have shown that crystal formation for some Cry proteins is also dependent on the expression of auxiliary proteins [10]. Therefore, it is reasonable to think that proteins from insect cells might help the formation of such large crystals inside the cytoplasm.

Another utility of introducing Cry protein genes into the baculovirus genome is the expression of single Cry proteins in insect cells for functional studies, since these proteins can be studied isolated without the contamination of other Cry proteins that is commonly found in $\mathrm{Bt}$ strains. Another possible advantage is the formation of large crystals made of Cry proteins $[19,21]$, which may facilitate structural studies of these proteins. The high level of expression and crystal formation ability of insect cells infected with recombinant baculoviruses carrying Cry protein genes could even facilitate synergistic studies between different toxins. Previous work has shown that Cry proteins can act synergistically, increasing their toxicity towards susceptible insects [22] and these studies will help researchers to choose which genes are more appropriate for being introduced into the genome of economically important crops.

Transgenic $B t$ crops have been commercialized for almost 10 years and several companies have been involved in developing this technology [23]. Transgenic plants expressing insecticidal proteins from $B t$ were grown on over 13 million ha in the United States and 22.4 million ha worldwide in 2004 and this technology is an important tool for the control of lepidopteran pests [24]. Since insects have the potential to develop resistance to Cry proteins [8] and the expression of different Cry proteins in the same plant can reduce or delay the onset of resistance [23], the search for new cry genes is an important strategy in order to construct a gene bank of possible candidates for introduction into economically important crops.

\section{ACKNOWLEDGMENTS}

We are grateful to Embrapa Recursos Genéticos e Biotecnologia for supplying A. gemmatalis and S. frugiperda larvae. This work was supported by the following Brazilian agencies: FINATEC, CAPES, CNPq, FAPDF, and PRONEX.

\section{Literature Cited}

1. Bietlot HPL, Vishnubhatla I, Carey PR, Pozsgay M, Kaplan H (1990) Characterization of the cysteine residues and disulfide link ages in the protein crystal of Bacillus thuringiensis. J Biochem 267:309-315

2. Bobrowski VL, Pasquali G, Zanettini MHB, Fiuza LM (2001) Detection of cry1 genes in Bacillus thuringiensis isolates from south of Brazil and activity against Anticarsia gemmatalis (Lepidoptera: Noctuidae) in Brazil. J Microbiol 32:105-109

3. Bohorova N, Maciel AM, Brito RM, Aguilart L, Ibarra JE, Hoisington D (1996) Selection and characterization of Mexican strains of Bacillus thuringiensis active against four major lepidopteran maize pests. Entomophaga 41:153-165

4. Chang JH, Choi JY, Jin BR, Roh JY, Olszewski JA, Seo SJ, O'Reilly DR, Je YH (2003) Improved baculovírus insecticide 
producing occlusion bodies that contain Bacillus thuringiensis insect toxin. J Invertebr Pathol 84:30-37

5. Christov NK, Imaishi H, Ohkawa H (1999) Green-tissue-specific expression of a reconstructed crylC gene encoding the active fragment of Bacillus thuringiensis delta-endotoxin in haploid tobacco plants conferring resistance to Spodoptera litura. Biosci Biotechnol Biochem 63:1433-1444

6. Crickmore N, Zeigler DR, Feitelson J, Schnepf E, Van Rie J, Lereclus D, Baum J, Dean DH (1998) Revision of the nomenclature of the Bacillus thuringiensis pesticidal crystal proteins. Microbiol Mol Biol Rev 62:807-813

7. de Maagd RA, bravo A, Berry C, Crickmore N, Schnepf E (2003) Structure, diversity, and evolution of protein toxins from sporeforming entomopathogenic bacteria. Ann Rev Genet 37:409-433

8. Ferre J, van Rie J (2002) Biochemistry and genetics of insect resistance to Bacillus thuringiensis. Ann Rev Entomol 47:501-533

9. Finney DJ (1971) Probit analysis. Cambridge, UK: Cambridge University Press

10. Ge B, Bideshi D, Moar JW, Federici BA (1998) Differential effects of helper proteins encoded by the cry $2 \mathrm{~A}$ and cry $11 \mathrm{~A}$ operons on the formation of Cry2A inclusions in Bacillus thuringiensis. FEMS Microbiol Lett 165:35-41

11. Granados RR, Guoxun L, Derksen CG, Mckenna KAA (1994) An insect cell line from Trichoplusia ni (BTI-Tn-5B1-4) susceptible to Trichoplusia $n i$ single enveloped nuclear polyhedrosis virus. J Invertebr Pathol 64:260-266

12. Hofmann C, Vanderbruggen H, Hofte H, Van Rie J, Jansens S, Van Mellaert H (1988) Specificity of Bacillus thuringiensis $\sigma$-endotoxin is correlated with the presence of high affinity binding sites in the border membrane of target insect midgets. Proc Natl Acad Sci USA 85:7844-7848

13. Honée G, Van de Salm T, Visser B, Nucleotide sequence of crystal protein gene isolated from B. thuringiensis subspecies entomocidus 60.5 coding of toxin highly active Spodoptera specie. Nucleic Acids Res 16:6240

14. Jarvis DL (1997) Baculovirus expression vectors. In: Miller LK (ed) The baculovirus. New York: Plenum Press, pp 389-341
15. Laemmli UK (1970) Cleavage of structural proteins during assembly of the head of bacteriphage T4. Nature 227:680685

16. Lin CH, Chen YY, Tzeng CC, Tsay HS, Chen LJ (2003) Expression of a Bacillus thuringiensis crylCa gene in plastid confers high insecticidal efficacy against tobacco cutworm - a Spodoptera insect. Bot Bull Acad Sin 44:199-210

17. Martens JW, Honee G, Zuidema D, Van Lent JWM, Visser B, Vlak JM (1990) Insecticidal activity of a bacterial crystal protein expressed by a recombinant baculovirus in insect cells. Appl Environ Microbiol 56:2764-2770

18. O'Reilly DR, Miller LK, Luckow VA (1992) Baculovirus expression vectors: A Laboratory Manual. New York: Freeman

19. Pang Y, Frutos R, Federici BA (1992) Synthesis and toxicity of full length and truncated bacterial CryIVD mosquitocidal proteins expressed in lepidopteran cells a baculovírus vector. J Gen Virol 73:89-101

20. Ribeiro BM, Crook NE (1998) Construction of occluded recombinant baculoviruses containing the full-length $c r y 1 \mathrm{Ab}$ and crylAc genes from Bacillus thuringiensis. Braz J Med Biol Res 31:763-769

21. Ribeiro BM, Crook NE (1993) Expression of full length and truncated forms of crystal protein genes from Bacillus thuringiensis subsp. Kurstaki in baculovírus and pathogenicity of the recombinant viruses. J Invertebr Pathol 62:121-130

22. Xue JL, Cai QX, Zheng DS, Yuan ZM (2005) The synergistic between Cry1Aa and Cry1C from Bacillus thuringiensis against Spodoptera exigua and Helicoverpa armigera. Lett Appl Microbiol 40:460-465

23. Zhao JZ, Cao J, Li Y, Collins HL, Roush RT, Earle ED, Shelton AM (2003) Transgenic plants expressing two Bacillus thuringiensis toxins delay insect resistance evolution. Nature Biotechnol 21:1493-1497

24. Zhao JZ, Cao J, Collins HL, Bates SL, Roush RT, Earle ED, Shelton AM (2005) Concurrent use of transgenic plants expressing a single and two Bacillus thuringiensis genes speeds insect adaptation to pyramided plants. Proc Natl Acad Sci USA 102:8426-8430 